144

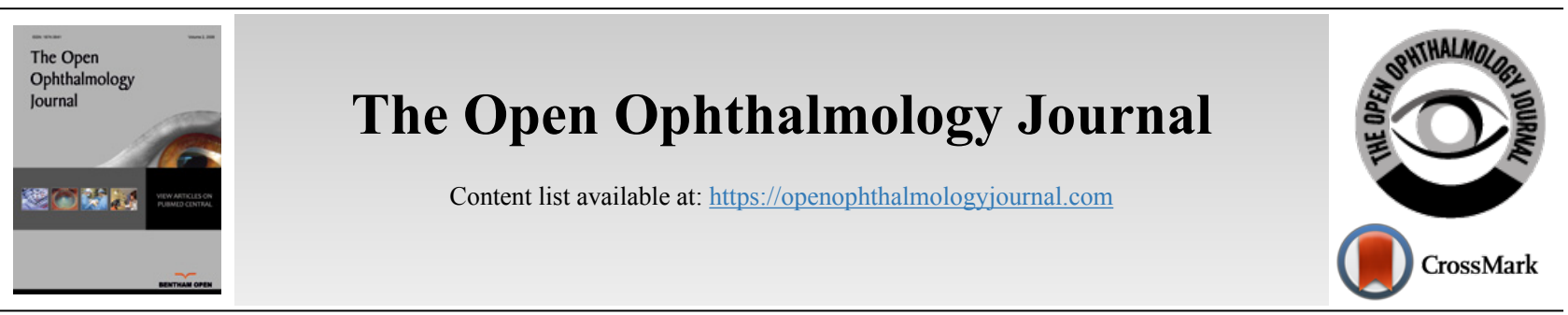

RESEARCH ARTICLE

\title{
Comparison of Visual Outcomes and Patient Satisfaction Following Cataract Surgery with Two Monofocal Intraocular Lenses: Clareon ${ }^{\circledR}$ vs AcrySof ${ }^{\circledR}$ IQ Monofocal
}

\author{
Smita Agarwal ${ }^{1}$ and Erin Thornel1 ${ }^{2, *}$ \\ ${ }^{1}$ Graduate School of Medicine, University of Wollongong, Wollongong Eye Specialists, Wollongong, Australia \\ ${ }^{2}$ Department of Wollongong Eye Specialists, Wollongong Eye Specialists, Wollongong, Australia
}

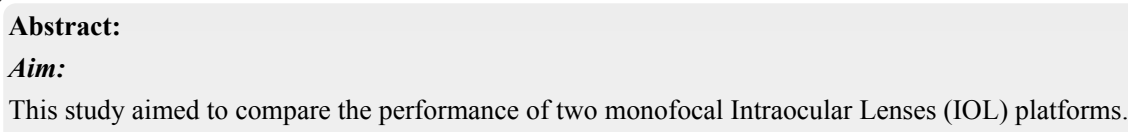

The Clareon ${ }^{\circledR}$ Intraocular Lens (IOL) is a relatively new monofocal lens platform designed to improve postoperative results compared to other monofocal platforms.

\section{Objective:}

This study aimed to assess and compare the visual and refractive outcomes, and incidence of YAG capsulotomy of the Clareon® IOL and a

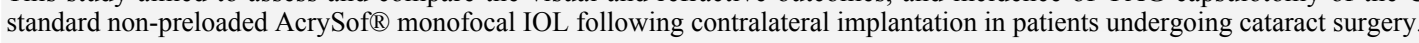

\section{Methods:}

A total of 20 patients ( 40 eyes; 12 female, average age $72.8 \pm 6.4$ years) who had undergone contralateral implantation of an AcrySof $\mathbb{R}$ IQ monofocal lens (SN60WF or SN6AT; Alcon; Texas, USA) and a Clareon ${ }^{\circledR}$ monofocal lens (CNAOT0; Alcon; Texas, USA) were selected. Uncorrected Distance Visual Acuity (UDVA), Contrast Sensitivity (CS), kinetic perimetry, and refraction were measured 1 month following the second surgery and subjective vision was measured 6 months following the second surgery using a quality-of-life questionnaire.

Results:

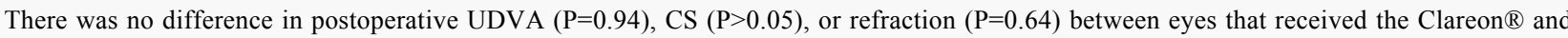

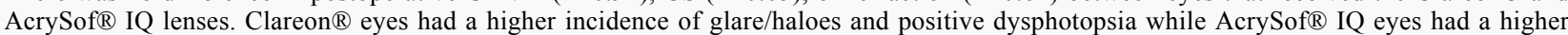
incidence of negative dysphotopsia. Patient satisfaction was similar between the groups $(\mathrm{P}=0.86)$, although $25 \%$ of patients reported more clarity in the eye that received the Clareon ${ }^{\circledR}$ lens. The incidence of posterior capsular opacification was low for both groups.

\section{Conclusion:}

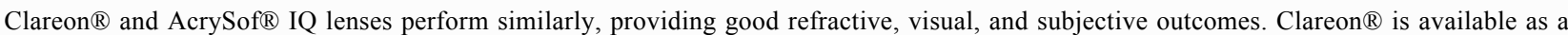
preloaded lens option and may reduce PCO and the need for Nd: YAG capsulotomy.

Keywords: Intraocular lens, Monofocal, Dysphotopsia, Glare, Haloes, Clarity, Cataract, Clareon®.

\section{Article History}

Received: February 22, 2021

Revised: May 18, 2021

Accepted: May 30, 2021

\section{INTRODUCTION}

Monofocal lenses are the most common type of Intraocular Lens (IOL) implanted during cataract surgery due to their predictable outcomes and low risk of visual artifacts. The Clareon ${ }^{\circledR}$ IOL is a relatively new aspheric hydrophobic acrylic monofocal IOL that claims to improve visual outcomes compared to other monofocal IOLs.

\footnotetext{
* Address correspondence to this author at the Department of Wollongong Eye Specialists, Wollongong Eye Specialists, Wollongong, Australia;

Tel: +61 24263 0500; Fax; +61 242630511 ;

E-mail: research@wescentre.com.au
}

Glare and positive dysphotopsias are caused largely by light reflecting off the edge or interior surfaces of the IOL onto the retina. They are usually associated with square edge IOL designs but can also be caused by peripheral non-imaging optic geometry [1]. Negative dysphotopsia is less understood but is believed to be caused by a gap between the retinal images formed by light bypassing the IOL and light passing through the IOL optic [2]. While positive dysphotopsia tends to not improve with time, negative dysphotopsia typically resolves on its own for most patients. It is difficult to predict who will 
develop photic symptoms following cataract surgery, although patients who are predisposed to haloes, e.g. patients with high preoperative Higher-Order Aberrations (HOAs), tend to be more susceptible to positive dysphotopsia while patients with a large functional retina may be more susceptible to negative dysphotopsia [3]. Small pupils and large angle kappa and angle alpha may also increase the likelihood of dysphotopsia [2, 3]. IOL designs have been adapted over time to prevent these symptoms. While square edge designs are successful at preventing Posterior Capsular Opacification (PCO), they cause the bending and reflection of light that results in photic phenomena. In response, more recent IOL designs have incorporated frosted or curved anterior edges. Larger optics, lower refractive power [3], positioning of the haptic junctions at 3 o'clock and 9 o'clock positions [4], and reverse optic capture technology [5], where the IOL overlays the capsulotomy edge, all help to prevent dysphotopsia. Visual outcomes can also be affected by glistenings, small vacuoles that form in the IOL over a period of years following surgery. Glistenings cause stray light and scattering, thereby degrading image quality and low light visual acuity [6].

The first AcrySof ${ }^{\circledR}$ platform became available in 1990 in the UK and since then, millions of AcrySof ${ }^{\circledR}$ IOLs have been implanted globally. While results are generally predictable with the AcrySof $\AA$ IOLs, some criticisms on the platform include issues with glistenings, surface haze, and dysphotopsia, as well as risks associated with a platform that is not preloaded, such as intraoperative scratches to the optic. To overcome these issues, the Clareon ${ }^{\circledR}$ platform and AutonoMe ${ }^{\mathrm{TM}}$ loading device were released in 2018.

The Clareon ${ }^{\circledR I O L}$ is an asymmetric, biconvex lens composed of hydrophobic acrylic material. It may prevent photic phenomena by way of its precision square edge design and fully functional $6 \mathrm{~mm}$ optic. The square edge may also prevent PCO by inhibiting epithelial cell migration. The lens is made of a novel hydrophobic acrylate/methacrylate copolymer that may improve clarity, and reduce surface haze, roughness and glistenings compared to other monofocal IOLs. The lens comes preloaded in the AutonoMe ${ }^{\mathrm{TM}}$ device, an innovative disposable delivery system powered by a carbon dioxide activated pump mechanism, which has been reported to promote less corneal inflammation and less endothelial cell loss compared to other preloaded cartridges [7].

Due to its relatively recent commercial availability, limited data is available regarding how the Clareon ${ }^{\circledR}$ lens behaves in situ; the bulk of available data comes from in vitro studies. This paper compares the visual outcomes of Clareon ${ }^{\circledR}$ and AcySof ${ }^{\circledR}$ IQ IOLs implanted contralaterally in patients undergoing cataract surgery, assessing visual acuity, photic phenomena, the incidence of $\mathrm{PCO}$, and patient satisfaction in a group of 20 patients over 12 months.

\section{METHODS}

A total of 20 patients (40 eyes) were recruited for the study (12 females, average age $72.8 \pm 6.4$ years). Patients were considered for inclusion if they had preoperative cylinder less than $1 \mathrm{D}$, had undergone bilateral routine phacoemulsification, and contralateral implantation of an AcrySof ${ }^{\circledR}$ monofocal IOL
(SN60WF or SN6AT; Alcon; Texas, USA) and a Clareon ${ }^{\circledR}$ monofocal IOL (CNAOT0; Alcon; Texas, USA). Patients were excluded for consideration if they had any underlying ocular pathology that may affect visual function (e.g. macular degeneration, glaucoma, epiretinal membrane, amblyopia, diabetic eye disease), experienced intra- or postoperative complications, preoperative cylinder exceeding $1 \mathrm{D}$, or received monovision or had vision corrected for near.

All surgeries were performed by a Single Surgeon (SA), whereby routine phacoemulsification and implantation of an AcrySof ${ }^{\circledR}$ monofocal IOL (SN60WF or SN6AT; Alcon; Texas, USA) and a Clareon ${ }^{\circledR}$ monofocal IOL (CNAOT0; Alcon; Texas, USA) were performed on contralateral eyes for each patient. Biometry measurements were performed using an IOLMaster 700 (Zeiss; Germany), and lens power was calculated using Barrett or Barrett toric (for eyes receiving a toricAcrySof ${ }^{\circledR}$ IOL) formula using target refraction of plano $\pm 0.25 \mathrm{D}$ for each eye. The procedures were performed under local or general anesthesia as per patient selection. Two $1 \mathrm{~mm}$ paracenteses were made at $180^{\circ}$ and a $2.3 \mathrm{~mm}$ and the main incision was made temporally. A 26-gauge cystotome was used to create a continuous curvilinear capsulorhexis. Following the surgery, patients were advised to commence ofloxacin (Allergan; Ocuflox; Dublin, Ireland) and prednisolone acetate/phenylephrine hydrochloride (Allergan; Prednefrin forte; Dublin, Ireland) eye drops following the surgery, applying one drop 2-hourly until bed-time. From the following day, the patients were advised to continue using ofloxacin and prednisolone acetate/phenylephrine hydrochloride eye drops applying one drop qid for 2 weeks and 3-4 weeks, respectively, and to commence using ketorolac (Allergan; Acular; Dublin, Ireland) eye drops applying one drop qid for 3 days. Patients attended a 1-month postoperative appointment within 4-6 weeks following the second surgery, where Uncorrected Distance Visual Acuity (UDVA), uncorrected Contrast Sensitivity (CS) (contrast sensitivity function i.e. CSF and modulation transfer function i.e. MTF), and refraction were measured. Visual acuity was measured under photopic conditions using a Snellen chart placed at 6 metres. Contrast sensitivity was measured using a sinus grating chart under mesopic conditions for CSF, and MTF was measured using an autorefractor (iTrace; Tracey Technologies LLC; Texas, USA). Kinetic perimetry was used to objectively measure the incidence of negative dysphotopsia [8] and was performed on a Humphrey Field Analyser 3 (Zeiss; Germany) using a white III 4 e stimulus with the variable speed at the following meridians: $0^{\circ}, 30^{\circ}, 90^{\circ}, 150^{\circ}, 180^{\circ}, 240^{\circ}, 270^{\circ}$, and $300^{\circ}$. The subjective vision was measured 6 months following the final surgery using a quality of vision questionnaire adapted from the PseudophakicDysphotopsia Questionnaire previously published by [9]. Subjective patient satisfaction was recorded as a number out of 10 , where 10 denotes very satisfied and 0 denotes very dissatisfied. Mean values recorded at the final 4-6 week postoperative appointment (i.e. following the second surgery) were compared between the Clareon ${ }^{\circledR}$ and AcrySof ${ }^{\circledR}$ IQ monofocal groups using paired T-tests and the Excel data analysis tool (Microsoft Corporation; Washington, USA) where $\mathrm{P}<0.05$ was assumed statistically significant. Lens specifications are listed in Table $\mathbf{1 .}$ 
Table 1. Product specifications for Clareon ${ }^{\circledR}$ and AcrySof ${ }^{\circledR}$ IQ monofocal IOLs.

\begin{tabular}{|c|c|c|}
\hline- & Clareon® & AcrySof® IQ \\
\hline Optic type & Asymmetric biconvex & Aspheric, biconvex \\
\hline Optic material & Hydrophobic acrylic & $6 \mathrm{~mm}$ \\
\hline Optic diameter & $6 \mathrm{~mm}$ & $13 \mathrm{~mm}$ \\
\hline Overall length & $13 \mathrm{~mm}$ & $0^{\circ}$ \\
\hline Haptic angulation & $0^{\circ}$ planar & STABLEFORCETM \\
\hline Haptic configuration & STABLEFORCETM & UV and blue light filtration \\
\hline Photoprotection & UV and blue light filtration & 1.55 \\
\hline Refractive index & 1.55 & $8.5 \mu \mathrm{m}(\mathrm{SN} 60 \mathrm{WF}) ; 9.3 \mu \mathrm{m}(\mathrm{SN} 6 \mathrm{AT})$ \\
\hline Edge curvature & $7.9 \mu \mathrm{m}$ & $0.5 \%$ \\
\hline Water content & $1.5 \%$ & $119.0(\mathrm{SN} 60 \mathrm{WF}) ; 119.2(\mathrm{SN} 6 \mathrm{AT})$ \\
\hline A Constant & 119.1 & \\
\hline
\end{tabular}

Table 2. Mean preoperative patient demographics.

\begin{tabular}{|c|c|c|c|}
\hline- & Clareon ${ }^{\circledR}(\mathbf{n}=\mathbf{2 0}$ eyes $)$ & AcrySof ${ }^{\circledR}$ IQ monofocal (n=20 eyes) \\
\hline Age & \multicolumn{3}{|c|}{$72.8 \pm 6.4$} \\
\hline $\begin{array}{c}\text { Gender (female } \\
\text { male) }\end{array}$ & \multicolumn{3}{|c|}{$\begin{array}{c}12 \\
8\end{array}$} \\
\hline CDVA (LogMAR) & $0.19 \pm 0.16$ & $0.25 \pm 0.14$ & 0.26 \\
\hline SE & $1.26 \pm 1.5$ & $1.27 \pm 0.98$ & 0.98 \\
\hline Sphere & $1.7 \pm 1.4$ & $0.6 \pm 1.1$ \\
\hline Cylinder & $-0.6 \pm 0.7$ & $-0.6 \pm 0.5$ \\
\hline
\end{tabular}

Table 3. Mean postoperative measurements at 4-6 weeks following the second surgery.

\begin{tabular}{|c|c|c|c|}
\hline- & $\begin{array}{c}\text { Clareon } \\
(\mathbf{n = 2 0} \text { eyes) }\end{array}$ & $\begin{array}{c}\text { AcrySof IQ monofocal } \\
(\mathbf{n}=\mathbf{2 0} \text { eyes) }\end{array}$ \\
\hline UDVA (LogMAR) & $0.03 \pm 0.06$ & $0.03 \pm 0.07$ \\
\hline CDVA (LogMAR) & $0.01 \pm 0.02$ & $0.02 \pm 0.05$ \\
\hline SE & $0.03 \pm 0.4$ & $-0.04 \pm 0.3$ & 0.94 \\
\hline Sphere & $0.12 \pm 0.4$ & $0.08 \pm 0.5$ & 0.40 \\
\hline Cylinder & $-0.46 \pm 0.4$ & $-0.31 \pm 0.2$ & 0.64 \\
\hline
\end{tabular}

\section{RESULTS}

Each group had similar preoperative Corrected Distance Visual Acuity (CDVA) $(\mathrm{P}=0.26)$ and refraction $(\mathrm{P}=0.98)$ (Table 2). Of the 20 eyes that had received AcrySof ${ }^{\circledR}$ IQ lenses, three eyes were implanted with SN6AT2, three eyes with SN6AT3, and one eye with SN6AT4, while all remaining eyes (13 eyes) were implanted with non-toric SN60WF lenses. No patients experienced peri- or postoperative complications, and no lenses were needed to be explanted.

\subsection{Refraction and Visual Acuity}

There was no difference in average postoperative refraction between the groups ( $\mathrm{P}=0.64)$, with 15 eyes $(83 \%)$ and $12(86 \%)$ eyes that received Clareon ${ }^{\circledR}$ lenses and AcrySof ${ }^{\circledR}$ IQ lenses, respectively, achieving postoperative spherical equivalent (SE) within $\pm 0.5 \mathrm{D}$ of the target refraction (Fig. 1A). There was no difference in postoperative monocular UDVA $(\mathrm{P}=0.94)$ or CDVA $(\mathrm{P}=0.4)$ between the two groups, with all patients achieving postoperative UDVA of 6/9 (equivalent to $20 / 30$ or $0.2 \operatorname{LogMAR}$ ) or better in each eye (Fig. 1B).

\subsection{Contrast Sensitivity}

There was no difference in CSF (Fig. 2A) or MTF (Fig. 2B) between the two groups $(\mathrm{P}>0.05)$.

\subsection{Photic Phenomena and Subjective Vision}

Average satisfaction was similar for both groups; 8.4 for Clareon $\AA$ eyes and 8.8 for AcrySof ${ }^{\circledR}$ IQ eyes $(\mathrm{P}=0.86)$. However, 5 patients $(25 \%)$ reported superior clarity in the eye that received the Clareon $\AA$ lens, while 1 patient $(5 \%)$ reported superior clarity in the eye that received the AcrySo ${ }^{\circledR}$ IQ lens and $70 \%$ reported similar clarity in both eyes. Higher numbers of patients who received Clareon ${ }^{\circledR}$ lenses experienced glare/haloes and positive dysphotopsia, however, no patients from this group reported negative dysphotopsia (Fig. 3A). No restriction in the visual field was detected using kinetic perimetry for either group (Fig. 3B).

\subsection{PCO}

No patients were presented with PCO in the eye that received the Clareon ${ }^{\circledR}$ IOL within the 3 years following surgery. Four patients $(20 \%)$ were presented with posterior capsular fibrotic changes in the eye that received the AcrySof ${ }^{\circledR}$ IQ monofocal IOLs with 3 patients $(15 \%)$ requiring $\mathrm{Nd}$ : YAG 
capsulotomy within three years following surgery.

\section{DISCUSSION}

Monofocal IOLs are the most commonly implanted type of IOL due to their predictable postoperative results and low incidence of photic phenomena compared to multifocal IOLs. Clareon ${ }^{\circledR}$ is a relatively new preloaded monofocal IOL platform that may help to enhance clarity and with reduced incidence of PCO and dysphotopsia. However, little is known regarding how the lens behaves in situ as previous studies have relied largely on in vitro experimental techniques due to the relatively recent commercial availability of the lens. To our knowledge, this is the first study to directly compare the performance of Clareon ${ }^{\circledR}$ and AcrySof ${ }^{\circledR}$ IQ IOLs in situ following contralateral implantation in a group of 20 human subjects undergoing cataract surgery.
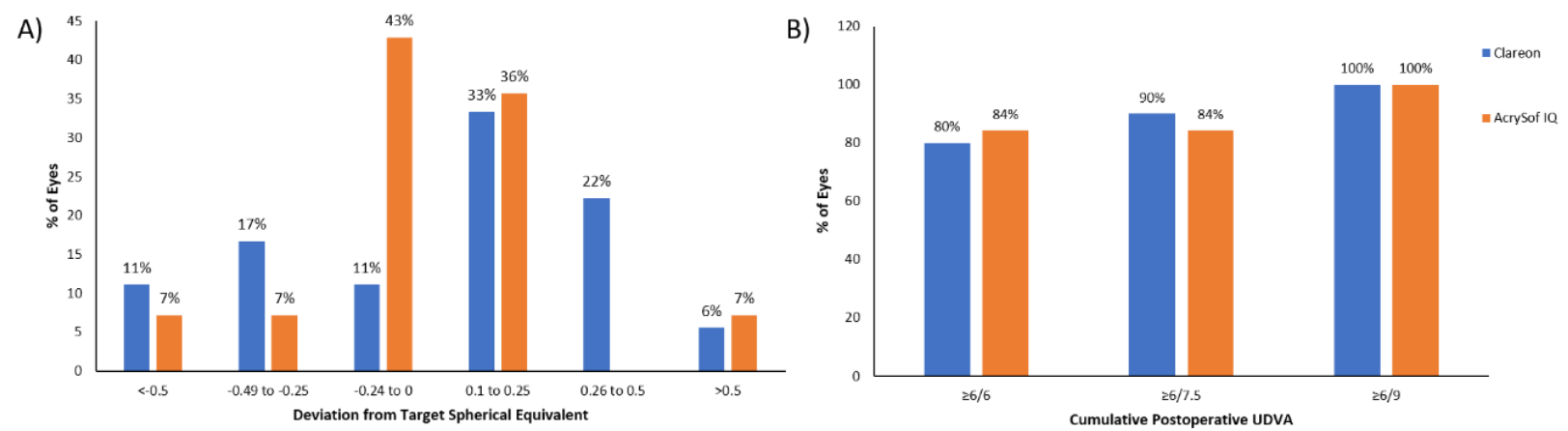

Fig. (1). A) Deviation in postoperative spherical equivalent from the plano target refraction in contralateral eyes that received Clareon or IQ monofocal IOLs 1 month after the final surgery. B) Cumulative postoperative monocular Uncorrected Distance Visual Acuity (UDVA) in contralateral eyes that received Clareon or IQ monofocal IOLs 1 month following the final surgery.

A)

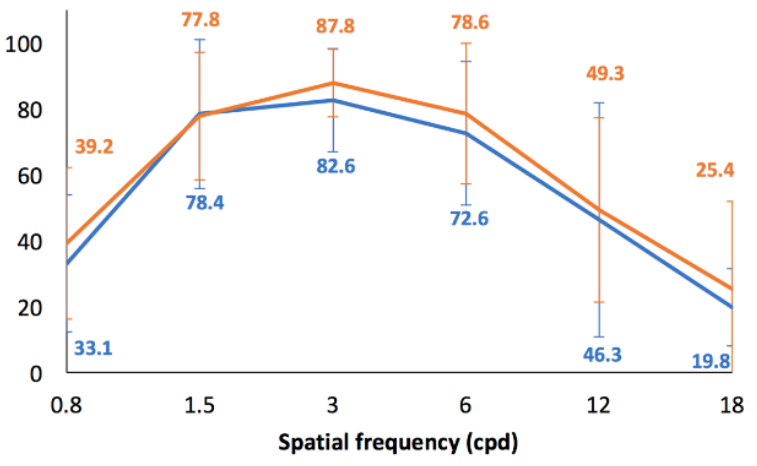

B) 1.0

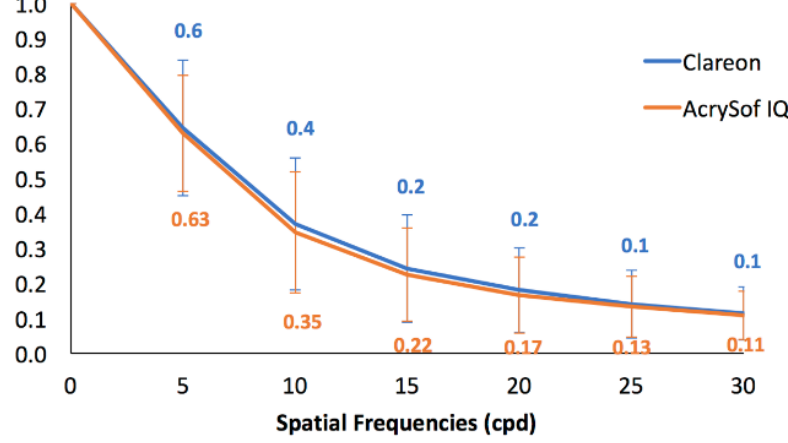

Fig. (2). A) Uncorrected monocular contrast sensitivity function and B) modulation transfer function of contralateral eyes that received Clareon ${ }^{\circledR}$ or AcrySof® IQ monofocal IOLs 4-6 weeks following the final surgery.

A)

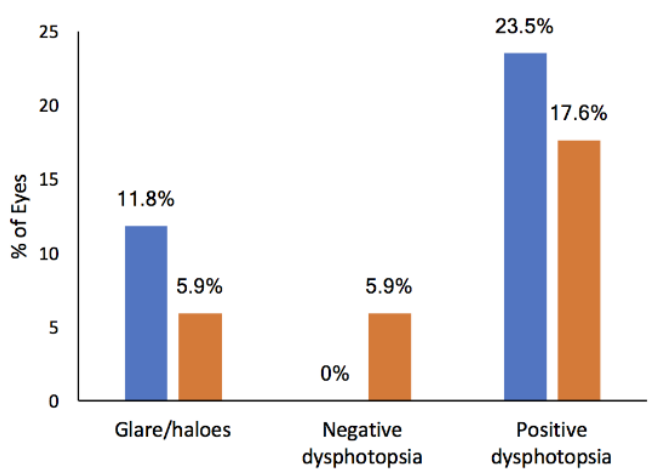

B)

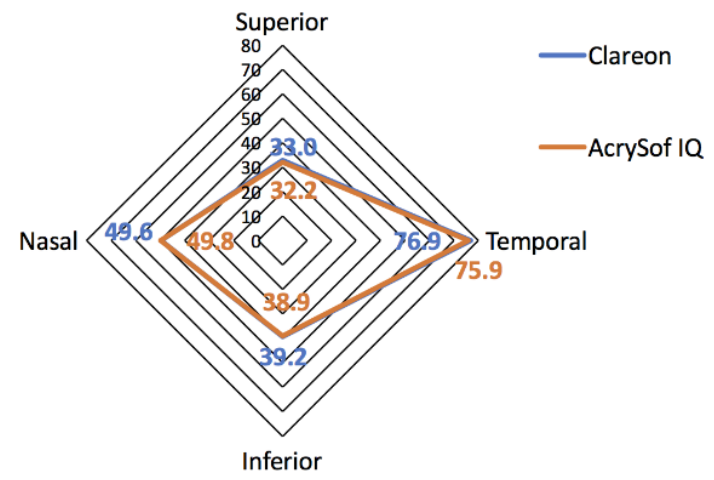

Fig. (3. A) Percentage of patients reporting photic symptoms 6 months after contralateral implantation of Clareon ${ }^{\circledR}$ and AcrySof ${ }^{\circledR}$ IQ monofocal IOLs. B) Manual kinetic perimetry visual field for contralateral eyes that received Clareon® or IQ IOLs 1 month following the final surgery. 
This study assessed patients who had undergone contralateral implantation of an AcrySof $\AA I Q$ IOL and a Clareon ${ }^{\circledR}$ IOL, and who fulfilled the inclusion criteria. Both groups achieved similar average postoperative spherical refraction and UDVA (Table 3), and a similar proportion of eyes within $\pm 0.5 \mathrm{D}$ of the target (Fig. 1A). Visual acuity and refractive results largely followed a normal distribution. Two outliers (considered to be $> \pm 0.5 \mathrm{D}$ from target SE) were present in each group for postoperative SE, caused by residual astigmatism. Recruitment was restricted to patients with preoperative cylinder less than $1.0 \mathrm{D}$ to prevent residual astigmatism, as toric versions of the Clareon ${ }^{\circledR}$ were not available at the time of the study. However, as toric lenses were selected for the first eye of each patient if the preoperative cylinder was $>0.75 \mathrm{D}, 7$ of the 20 eyes that received AcrySof ${ }^{\circledR}$ IQ lenses received toric SN6AT lenses. This may have resulted in the residual postoperative cylinder in eyes that received Clareon ${ }^{\circledR}$ lenses, although there was no statistical difference between the groups postoperatively ( $\mathrm{P}=$ 0.29 ) and outliers were present in both groups. Both groups were also within the guidelines recommended by the Royal College of Ophthalmologists; $85 \%$ within $\pm 1.0 \mathrm{D}$ and $55 \%$ within $\pm 0.5 \mathrm{D}$ of the target refraction [10]. Long-term refractive stability was stable up to 12 months. However, in vitro analysis has reported less axial displacement and related dioptric power shift for SN60WF and Clareon ${ }^{\circledR}$ IOLs compared to other IOLs [11], suggesting that refraction is likely to remain stable long-term following implantation.

Quality and clarity of vision are dependent on IOL material, surface qualities, and refractive index. While AcrySof ${ }^{\circledR}$ IQ and Clareon ${ }^{\circledR}$ IOLs are both composed of a similar hydrophobic acrylate/methacrylate copolymer material with a refractive index of 1.55 , Clareon ${ }^{\circledR}$ IOLs have a slightly higher water percentage (i.e. $1.5 \%$ versus $0.5 \%$ ). Analysis of artificially aged Clareon ${ }^{\circledR}$ lenses have shown improved surface smoothness and decreased glistenings compared to competitor lenses [12]. This is likely due to the high-water content of the lens, resulting in less light scatter, improving image quality, and maintaining CS. A higher proportion of patients (i.e. $25 \%$ vs $5 \%$ ) reported superior clarity in the eye that received Clareon ${ }^{\circledR}$ IOL, which is consistent with previous reports and likely due to superior surface smoothness. There was no difference in CSF or MTF between the two groups for this study (Figs. 2A, B). As glistening develop over time, increasing for up to 10-15 years following implantation [6], it is not unexpected to see no difference within the first 3 years following surgery. To fully assess postoperative CS, and incidence of glistenings and PCO, a long-term study will be required.

Both AcrySof ${ }^{\circledR}$ IQ and Clareon ${ }^{\circledR}$ lenses feature square edge designs that aim to prevent PCO by inhibiting epithelial cell migration. Studies that have compared the incidence of PCO following implantation of SN60WF and Clareon ${ }^{\circledR}$ IOLs in rabbit and explanted capsular bags from human cadavers reported no difference in $\mathrm{PCO}$ incidence or progression rates $[13,14]$. However, a large-scale meta-analysis reported that incidence of PCO requiring Nd: YAG capsulotomy within the first year of surgery in humans was higher in eyes that received SN60WF lenses compared to Clareon ${ }^{\circledR}$ lenses $(1.44 \%$ versus
$0.62 \%$, respectively) [15]. This study reported Nd: YAG capsulotomy incidence rate of $15 \%$ in eyes that received AcrySof ${ }^{\circledR}$ IQ lenses, while no PCO was recorded in eyes that received Clareon ${ }^{\circledR}$ lenses within 3 years of the final surgery. The first patient to develop PCO had a posterior subcapsular cataract preoperatively, so the opacification is likely to have been caused by posterior capsular fibrosis. Since then, no further patients have presented with complaints of PCO symptoms. A low incidence of PCO was expected in Clareon ${ }^{\circledR}$ eyes due to the precise square edge design of the IOL. Incidence in eyes that received the AcrySof $\mathbb{R}$ IQ IOLs was higher than previously reported [16]. The small sample size of this study and the inclusion of patients with posterior subcapsular cataracts preoperatively make these results difficult to interpret reliably.

Photic phenomena, such as glare/haloes and dysphotopsias, are in part contributed to straight edge optic designs and peripheral non-imaging optic geometry [1]. Photic phenomena were measured using two methods; subjective questionnaire and kinetic perimetry. For subjective symptoms, a questionnaire was used that was adapted from the Pseudophakic Dysphotopsia Questionnaire previously published by Kinard et al. [9]. While negative dysphotopsia

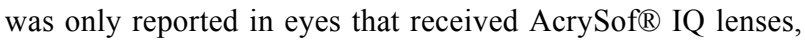
positive dysphotopsia was more commonly reported in eyes that received Clareon ${ }^{\circledR}$ IOLs compared to eyes that received AcrySof ${ }^{\circledR}$ IQ IOLs (23.5\% versus $17.6 \%$, respectively; Fig. 3A). Lens edge designs are a trade-off; a sharp edge prevents PCO but induces positive dysphotopsia. To limit positive dysphotopsia, IOL designs have introduced frosted or curved edges to prevent the reflection of light back onto the IOL. Clareon ${ }^{\circledR}$ lenses have a lower radius of curvature on the posterior edge ( $7.9 \mu \mathrm{m}$ versus $8.5 \mu \mathrm{m}$ and $9.3 \mu \mathrm{m}$ for SN60WF and SN6AT, respectively) [17]. Although slight, this difference could explain the higher incidence of positive dysphotopsia as well as the lower rate of capsular fibrosis in eyes that received Clareon ${ }^{\circledR}$ lenses. The etiology of negative dysphotopsia is less understood but is postulated to be caused by the bending of incoming light resulting in a gap forming between the retinal images produced by light bypassing the lens and light being refracted by the optic [2]. Methods to objectively measure dysphotopsia have traditionally been elusive. However, kinetic perimetry has been used to objectively measure negative dysphotopsia symptoms [8]. Briefly, Goldmann kinetic perimetry was used to measure the visual field of pseudophakic patients, and temporal field restrictions and temporal scotomas were detected that corresponded with the location of subjectively reported shadows [8]. When measured subjectively, $5.9 \%$ of patients reported experiencing negative dysphotopsia in the eye that received AcrySof ${ }^{\circledR}$ IQ lens (Fig. 3A). No patients reported such symptoms in the eye that received the Clareon ${ }^{\circledR}$ lens (Fig. 3A). However, when measured using kinetic perimetry, there was no difference in visual fields between the groups, with both groups lying within the population norm (Fig. 3B). This may suggest discrepancies between visual field defects and symptoms perceived by the patient or may suggest that temporal field restriction as measured by kinetic perimetry is not sensitive enough to reliably predict dysphotopsia symptoms in a sample group of 
this size. This may be caused by the fact that standard kinetic perimetry tests only measure up to $90^{\circ}$ of the peripheral visual field. Despite differences in photic symptoms, both groups reported similar rates of satisfaction ( 8.4 and 8.8 out of 10 for Clareon ${ }^{\circledR}$ and AcrySof $\AA$ IQ eyes, respectively; $P>0.05$ ), suggesting that such symptoms may not be clinically significant or impact quality of life.

The Clareon ${ }^{\circledR}$ IOL comes preloaded in the AutonoMe $\mathrm{e}^{\mathrm{TM}}$ delivery system. The automated preloaded delivery system of the AutonoMe $\mathrm{TM}^{\mathrm{TM}}$ device has been reported to inflict less wound trauma during IOL insertion compared to manual insertion, leading to reduced incidence of Descemet membrane detachment, posterior gape, and wound retraction [18]. According to the surgeon, during this study, the delivery system appears to be precise and predictable with few minor complications. The carbon dioxide pump failed in one case and the trailing haptic was found to be stuck to the optic in a few cases. The haptic could be easily removed from the optic and no further intra- or postoperative complications were encountered for any patient. All IOLs appeared well centered in the eye following surgery and remained stable at follow-up.

Limitations of this study include a small sample size due to a limited patient pool as patients were recruited from the cohort that had incidentally undergone contralateral implantation of an AcrySof ${ }^{\circledR}$ IOL and a Clareon ${ }^{\circledR}$ IOL as a result of a change in surgeon preference and protocol between the surgeries, and relatively short follow-up time. Some complications, such as glistenings, which can reduce contrast sensitivity, can take 5-10 years to develop while clinically significant PCO may take 4-5 years. Therefore, a long-term comparative study will be required to effectively compare CS and the incidence of PCO. However, no patients have presented until recently complaining of PCO symptoms in the eye that received the Clareon ${ }^{\circledR}$ IOL. Additionally, the inclusion of eyes with toric IOLs may have skewed photic phenomena resulted as toric IOLs are implanted along the steep axis while monofocal IOLs are implanted inferotemporally to minimise photic phenomena as previously reported and as per surgeon preference [4]. Toric versions of the Clareon ${ }^{\circledR}$ IOL were not available at the time of the study, but are now readily available. Allowing treatment of astigmatism in the eyes that received Clareon ${ }^{\circledR}$ IOLs may have improved postoperative visual outcomes, although there was no statistically significant difference in postoperative refraction between the groups $(\mathrm{P}=0.64)$.

\section{CONCLUSION}

The Clareon ${ }^{\circledR}$ IOL does not appear to be inferior to the AcrySof ${ }^{\circledR}$ IQ IOL, achieving similar visual, refractive, and subjective outcomes. However, the lower radius of curvature on the posterior edge of the Clareon ${ }^{\circledR}$ lens, while potentially leading to lower incidence of PCO and Nd; YAG capsulotomy, may induce more positive dysphotopsia than AcrySof ${ }^{\circledR}$ IQ lenses. Benefits of the Clareon ${ }^{\circledR}$ system over other monofocal IOLs may include improved visual clarity, lower incidence of Nd: YAG capsulotomy for PCO, and ease-of-use of the AutonoMe ${ }^{\mathrm{TM}}$ delivery system. Due to the small size of this study, larger long-term prospective studies will be required to help elucidate, as well as to determine differences in the long- term incidence of glistenings and PCO between the lens platforms.

\section{LIST OF ABBREVIATIONS}

$\begin{array}{lll}\text { IOL } & =\text { Intraocular Lens } \\ \text { UDVA } & =\text { Uncorrected Distance Visual Acuity } \\ \text { CS } & =\text { Contrast Sensitivity } \\ \text { HOAs } & =\text { Higher-Order Aberrations } \\ \text { PCO } & =\text { Posterior Capsular Opacification } \\ \text { CSF } & =\text { Contrast Sensitivity Function } \\ \text { MTF } & =\text { Modulation Transfer Function } \\ \text { CDVA } & =\text { Corrected Distance Visual Acuity } \\ \text { SE } & =\text { Spherical Equivalent }\end{array}$

\section{ETHICAL STATEMENT}

Ethics approval was not required according to the applicable HREC committee due to the retrospective nature of the study. This research was carried out according to the tenets of the declaration of helsinki.

\section{CONSENT FOR PUBLICATION}

Informed written consent to participate and consent for publication were obtained from all participants.

\section{AVAILABILITY OF DATA AND MATERIALS}

Not applicable.

\section{FUNDING}

None.

\section{CONFLICT OF INTEREST}

No financial support was received for this study. Dr. Erin thornell has no conflicts of interest to disclose. Dr. Smita agarwal is a member of the advisory board for alcon, the manufacturer of both of the lenses used for this study.

\section{ACKNOWLEDGEMENTS}

Declared none.

\section{REFERENCES}

[1] Das KK, Werner L, Collins S, Hong X. In vitro and schematic model eye assessment of glare or positive dysphotopsia-type photic phenomena: Comparison of a new material IOL to other monofocal IOLs. J Cataract Refract Surg 2019; 45(2): 219-27. [http://dx.doi.org/10.1016/j.jcrs.2018.09.017] [PMID: 30471850]

[2] Holladay JT, Simpson MJ. Negative dysphotopsia: Causes and rationale for prevention and treatment. J Cataract Refract Surg 2017; 43(2): 263-75.

[http://dx.doi.org/10.1016/j.jcrs.2016.11.049] [PMID: 28366376]

[3] Holladay JT, Zhao H, Reisin CR. Negative dysphotopsia: The enigmatic penumbra. J Cataract Refract Surg 2012; 38(7): 1251-65. [http://dx.doi.org/10.1016/j.jcrs.2012.01.032] [PMID: 22727295]

[4] Henderson BA, Yi DH, Constantine JB, Geneva II. New preventative approach for negative dysphotopsia. J Cataract Refract Surg 2016; 42(10): 1449-55.

[http://dx.doi.org/10.1016/j.jcrs.2016.08.020] [PMID: 27839599]

[5] Masket S, Fram NR, Cho A, Park I, Pham D. Surgical management of negative dysphotopsia. J Cataract Refract Surg 2018; 44(1): 6-16. [http://dx.doi.org/10.1016/j.jcrs.2017.10.038] [PMID: 29502619]

[6] Mönestam E, Behndig A. Change in light scattering caused by 
glistenings in hydrophobic acrylic intraocular lenses from 10 to 15 years after surgery. J Cataract Refract Surg 2016; 42(6): 864-9. [http://dx.doi.org/10.1016/j.jcrs.2016.02.047] [PMID: 27373393]

[7] Mastropasqua L, Toto L, D'Ugo E, et al. In vivo and in vitro results in an automated preloaded delivery system for IOL implantation in cataract surgery. Int Ophthalmol 2019.

[http://dx.doi.org/10.1007/s10792-019-01154-0] [PMID: 31451986]

[8] Makhotkina NY, Berendschot TT, Nuijts RM. Objective evaluation of negative dysphotopsia with Goldmann kinetic perimetry. J Cataract Refract Surg 2016; 42(11): 1626-33.

[http://dx.doi.org/10.1016/j.jcrs.2016.09.016] [PMID: 27956290]

[9] Kinard K, Jarstad A, Olson RJ. Correlation of visual quality with satisfaction and function in a normal cohort of pseudophakic patients. J Cataract Refract Surg 2013; 39(4): 590-7.

[http://dx.doi.org/10.1016/j.jcrs.2012.11.023] [PMID: 23395326]

[10] National institute for health and care excellence. 2017. Available from: https://www.nice.org.uk/guidance/ng77/evidence/full-guideline-pdf-46 55997901

[11] Lane S, Collins S, Das KK, et al. Evaluation of intraocular lens mechanical stability. J Cataract Refract Surg 2019; 45(4): 501-6. [http://dx.doi.org/10.1016/j.jcrs.2018.10.043] [PMID: 30686704]

[12] Werner L, Thatthamla I, Ong M, et al. Evaluation of clarity characteristics in a new hydrophobic acrylic IOL in comparison to commercially available IOLs. J Cataract Refract Surg 2019; 45(10): 1490-7.

[http://dx.doi.org/10.1016/j.jcrs.2019.05.017] [PMID: 31399323]

[13] Werner L, Ellis N, Heczko JB, et al. In vivo evaluation of a new hydrophobic acrylic intraocular lens in the rabbit model. J Cataract Refract Surg 2018; 44(12): 1497-502.

[http://dx.doi.org/10.1016/j.jcrs.2018.07.040] [PMID: 30228013]

[14] Hillenmayer A, Wertheimer CM, Kassumeh S, et al. Evaluation of posterior capsule opacification of the Alcon Clareon IOL $v$ s the Alcon Acrysof IOL using a human capsular bag model. BMC Ophthalmol 2020; 20(1): 77.

[http://dx.doi.org/10.1186/s12886-020-01349-5] [PMID: 32103739]

[15] Von Tress M, Marotta JS, Lane SS, Sarangapani R. A meta-analysis of $\mathrm{Nd}$ :YAG capsulotomy rates for two hydrophobic intraocular lens materials. Clin Ophthalmol 2018; 12: 1125-36.

[http://dx.doi.org/10.2147/OPTH.S161380] [PMID: 29950808]

[16] Ursell PG, Dhariwal M, O'Boyle D, Khan J, Venerus A. 5 Year incidence of YAG capsulotomy and posterior capsular opacification after cataract surgery with single-piece monofocal intraocular lenses: A real-world evidence study of 20, 763 eyes. Eye (Lond) 2020; 34 : 960-8.

[http://dx.doi.org/10.1038/s41433-019-0630-9] [PMID: 31616057]

[17] Nanavaty MA, Zukaite I, Salvage J. Edge profile of commercially available square-edged intraocular lenses: Part 2. J Cataract Refract Surg 2019; 45(6): 847-53.

[http://dx.doi.org/10.1016/j.jcrs.2018.12.004] [PMID: 30929976]

[18] Cennamo M, Favuzza E, Salvatici MC, Giuranno G, Buzzi M, Mencucci R. Effect of manual, preloaded, and automated preloaded injectors on corneal incision architecture after IOL implantation. J Cataract Refract Surg 2020; 46(10): 1374-80.

[http://dx.doi.org/10.1097/j.jcrs.0000000000000295]

[PMID:

\section{(c) 2021 Agarwal and Thornell}

This is an open access article distributed under the terms of the Creative Commons Attribution 4.0 International Public License (CC-BY 4.0), a copy of which is available at: (https://creativecommons.org/licenses/by/4.0/legalcode). This license permits unrestricted use, distribution, and reproduction in any medium, provided the original author and source are credited. 